\title{
Nigrostriatal Dopaminergic Neurodegeneration in the Weaver Mouse Is Mediated via Neuroinflammation and Alleviated by Minocycline Administration
}

\author{
Jun Peng, ${ }^{1}$ Lin Xie, ${ }^{1}$ Fang Feng Stevenson, ${ }^{1}$ Simon Melov, ${ }^{1}$ Donato A. Di Monte, ${ }^{2}$ and Julie K. Andersen ${ }^{1}$ \\ ${ }^{1}$ Buck Institute for Age Research, Novato, California 94945, and 2Parkinson's Institute, Sunnyvale, California 94089
}

\begin{abstract}
The murine mutant weaver (gene symbol, $w v$ ) mouse, which carries a mutation in the gene encoding the G-protein inwardly rectifying potassium channel Girk2, exhibits a diverse range of defects as a result of postnatal cell death in several different brain neuron subtypes. Loss of dopaminergic nigrostriatal neurons in the weaver, unlike cerebellar granule neuronal loss, is via a noncaspase-mediated mechanism. Here, we present data demonstrating that degeneration of midbrain dopaminergic neurons in weaver is mediated via neuroinflammation. Furthermore, in vivo administration of the anti-inflammatory agent minocycline attenuates nigrostriatal dopaminergic neurodegeneration. This has novel implications for the use of the weaver mouse as a model for Parkinson's disease, which has been associated with increased neuroinflammation.
\end{abstract}

Key words: weaver; dopaminergic midbrain neurons; caspase-independent cell death; microglial activation; minocycline; Parkinson

\section{Introduction}

Weaver $(w v)$ is a naturally occurring murine mutation in the Girk2 gene, which encodes a G-protein-activated inwardly rectifying potassium ion channel (Patil et al., 1995). Mice carrying two copies of the mutant gene display ataxia, hyperactivity, and tremor (Caviness and Rakic, 1978). These neurological defects are associated with neuronal degeneration during postnatal development in the ventral midbrain among dopaminergic neurons of the substantia nigra (SN) and retrorubral nucleus (Schmidt et al., 1982; Roffler-Tarlov and Graybiel, 1984; Triarhou et al., 1988; Graybiel et al., 1990; Roffler-Tarlov et al., 1996), within granule cells (Rezai and Yoon, 1972; Rakic and Sidman, 1973a,b) and Purkinje cells (Blatt and Eisenman, 1985; Herrup and Trenkner, 1987; Smeyne and Goldowitz, 1990) of the cerebellum and the deep cerebellar nuclei (Maricich et al., 1997). The Girk2wv defect appears to initiate different types of cell death based on the morphological appearance of dying neurons in these different brain regions. Affected cerebellar granule neurons display the morphological characteristics of classic apoptosis, including chromatin condensation and aggregation to the nuclear margin, cytoplasmic shrinkage, and membrane blebbing (Savitz and Rosenbaum, 1998). In addition, discreet chromatin cleavage as indicated by DNA end-labeling is also observed in dying granule neurons (Smeyne and Goldowitz, 1989; Harrison and Roffler-Tarlov, 1998). In contrast, dying midbrain dopaminergic neurons can-

Received April 30, 2006; revised Sept. 21, 2006; accepted Sept. 22, 2006.

This work was supported by grants from the National Institutes of Health (J.K.A., S.M.). We thank Dr. Susan Roffler-Tarlov for advice and discussion on morphological issues related to the $\mathrm{p} 35$ transgenic expression studies in the weaver mice.

Correspondence should be addressed to Julie K. Andersen, Buck Institute for Age Research, 8001 Redwood Boulevard, Novato, CA 94945. Email: jandersen@buckinstitute.org.

DOI:10.1523/JNEUROSCI.3447-06.2006

Copyright $\odot 2006$ Society for Neuroscience $\quad$ 0270-6474/06/2611644-08\$15.00/0 not be detected by assays for end-labeled cells and do not display classic morphological features of apoptosis (Oo et al., 1996; Migheli et al., 1997, 1999). Instead, cell death is characterized by lack of chromatin clumping, maintenance of neuronal shape, and unshrunken cytoplasm in the retrorubral nucleus (A8) and the substantia nigra pars compacta ( $\mathrm{SNpc}$ ) (A9) regions, whereas the adjacent A10, which contains dopaminergic cells in the medial portion of the ventral midbrain, is mostly spared (Roffler-Tarlov and Graybiel, 1984, 1986). The selective vulnerability in the ventral midbrain is explained by the fact that the dopaminergic neurons of the A8 and A9 express Girk2, whereas little or no Girk2 is found within A10 neurons (Schein et al., 1998). However, the molecular mechanisms involved in Girk $2 w v$-mediated dopaminergic cell death are not known.

To verify that dopaminergic cell death in the midbrains of weaver mice does not occur via apoptosis, we expressed the general caspase inhibitor baculoviral p35 and examined cell loss in the midbrain. Expression of p35 did not attenuate death of dopaminergic neurons in the weaver ventral midbrain (supplemental data, available at www.jneurosci.org as supplemental material). To better understand the mechanisms underlying selective dopaminergic cell death in this brain region, we performed microarray analyses to assess gene expression in the weaver SN during the period of selective dopaminergic neurodegeneration. We discovered, among alterations in expression of other genes, an elevation in expression levels of the mRNA for the microglialassociated inflammatory gene $\beta 2$-microglobulin and several major histocompatibility complex (MHC) class I proteins. These changes were subsequently found to be associated with increased expression of the corresponding proteins within nigral dopaminergic neurons in the weaver midbrain along with increased levels of microglial activation. Minocycline, an anti-inflammatory agent and inhibitor of microglial activation, was found to atten- 
uate Girk $2 w v$-induced nigrostriatal dopaminergic neurodegeneration both in isolated mesencephalic cultures and after in vivo administration in weaver mice. In addition, weaver mice treated with minocycline displayed a significant improvement in locomotor behavior but not ataxia. This suggests that neuroinflammation constitutes a major constituent involved in the selective nigrostriatal neurodegeneration in the weaver mouse. Given that neuroinflammation appears to be a major mediator of dopaminergic neurodegeneration associated with this same set of neurons in Parkinson's disease (PD) as well as in various Parkinsonian animal models, this study has novel implications in terms of the use of weaver as a model for this disorder and for the associated testing of anti-inflammatory therapeutics.

\section{Materials and Methods}

Materials. PCR reagents, DNA polymerase, and positively charged nylon membranes for genotyping were obtained from Roche Molecular Biochemicals (Indianapolis, IN). Rabbit and sheep anti-tyrosine hydroxylase $(\mathrm{TH})$ polyclonal antibodies were purchased from Chemicon (Temecula, CA). Rabbit anti-p35 polyclonal antibody was obtained from Biocarta (Carlsbad, CA). Rabbit anti-mouse cleaved caspase- 3 polyclonal antibody was obtained from Cell Signaling Technology (Beverly, MA). Rabbit anti-glial fibrillary acidic protein (GFAP) antibody was purchased from Sigma-Aldrich (St. Louis, MO). Mouse anti-mouse $\mathrm{H}-2 \mathrm{~K}^{\mathrm{b}} \mathrm{MHC}$ class I alloantigen antibody was from BD Biosciences (San Jose, CA). Mouse anti-mouse $\beta 2$-microglobulin antibody was obtained from Research Diagnostics (Flanders, NJ). Rat anti-mouse CD11b antibody was purchased from Serotec (Raleigh, NC). Protease inhibitor mixture and monoclonal anti- $\beta$-actin antibody were purchased from Sigma. Polyvinylidene difluoride (PVDF) membrane and SDS-PAGE gels were obtained from Bio-Rad (Hercules, CA).

Animals and treatment. All mice were maintained on B6CBACa-A ${ }^{\mathrm{w}-\mathrm{J} /}$ A-Kcnj $6^{\text {wv }}$ hybrid background and were offspring of breeding pairs obtained from The Jackson Laboratory (Bar Harbor, ME). A transgene consisting of the neuron-specific enolase promoter and the p35 coding sequence was microinjected into fertilized $\mathrm{B} 6 \mathrm{C} 3 \mathrm{~F} 1$ oocytes to generate p35 transgenic mice as described previously (Viswanath et al., 2000). Mice used for this study were offspring of breeding pairs between female $+/ w v, \mathrm{p} 35+/-$, or $w v / w v, \mathrm{p} 35+/-$ mice, and male $+/ w v, \mathrm{p} 35+/-$ mice. The presence of the $\mathrm{p} 35$ transgene was identified by DNA slot blot analysis as described previously (Viswanath et al., 2000). Weaver genotypes were determined by a restriction site-generating PCR protocol as described previously (Peng et al., 2002). For minocycline treatment, mice were administered minocycline- $\mathrm{HCl}$ (60 mg/kg/d in $5 \%$ sucrose; Sigma) or $5 \%$ sucrose by oral gavage from postnatal day 10 (P10) through P24.

Immunohistochemistry. For immunofluorescent staining, sections were fixed and processed for immunostaining as described previously (Peng et al., 2004). Primary antibodies used in this study were as follows: sheep anti-tyrosine hydroxylase (1:500), rabbit anti-p35 (1:200), rabbit anti-GFAP (1:500), mouse anti-H- $2 \mathrm{~K}^{\mathrm{b}}(1: 100)$, mouse anti- $\beta 2$ microglobulin (1:100), and rat anti-CD11b (1:150). The secondary antibodies were Alexa Fluro 488-, 594- or 647-conjugated donkey antimouse, anti-rat, anti-sheep, or anti-rabbit IgG (1:200-500; Invitrogen, San Diego, CA). Nuclei were counterstained with 4',6-diamidino-2phenylindole (DAPI) using proLong Gold anti-fade reagent (Invitrogen), and fluorescence signals were detected with an LSM 510 NLO Confocal Scanning System mounted on an Axiovert 200 inverted microscope (Carl Zeiss, Thornwood, NY) equipped with a two-photon Chameleon laser (Coherent, Kitchener, Ontario, Canada). Images were acquired using LSM 510 Imaging Software (Carl Zeiss). Four-color images were scanned using Argon, $543 \mathrm{HeNe}, 633 \mathrm{HeNe}$, and Chameleon (750-780 $\mathrm{nm}$ for DAPI) lasers. IMARIS (Bitplane, Zurich, Switzerland) imaging software was used for three-dimensional image reconstruction. For quantitation of CD11b immunoreactivity, each midbrain section was viewed at low power ( $10 \times$ objective), and the $\mathrm{SNpc}$ was outlined by using the set of anatomical landmarks. Then at a random start, the number of CD11b-positive cells was counted at high power $(100 \times$; numerical aper- ture, 1.30 oil immersion objective). After all sections from the SNpc were analyzed, the numbers of CD11b-positive cells within the SNpc were counted for each animal by using SIMPLE PCI (Compix, Cranberry Township, PA) (Galvan et al., 2006). For immunohistochemical analysis of cleaved caspase-3, sections were incubated with rabbit anti-cleaved caspase-3 (1:200) antibody overnight at $4^{\circ} \mathrm{C}$, washed with PBS, and incubated with biotinylated secondary antibodies $(1: 200)$ for $1 \mathrm{~h}$ at room temperature. Color development was done with the Vectastain ABC kit in combination with $3,3^{\prime}$-diaminobenzidine reagents following the instructions of the manufacturer. Subsequently, the sections were counterstained with hematoxylin. For stereology studies, cryostat-cut sections were taken through the entire midbrain. TH-positive neurons were immunolabeled and counted as described previously (Peng et al., 2004). Controls included omitting or preabsorbing primary or omitting secondary antibodies.

Silver staining. Dying neurons in the ventral midbrains of P24 littermates were marked by a silver stain, and the numbers of silver stained neurons in the A9 region were performed from four mice per group using methods described in detail previously (Oo et al., 1996). Unbiased stereological counts of silver-stained cells were obtained from the A9 by using a computer-assisted image analysis system consisting of a Zeiss Axioplan2 photomicroscope equipped with a Neurolucida Stereo Investigator (MicroBrightField, Williston, VT). The number of silver-stained neurons in the A9 was calculated by using methods described in detail previously (Coggeshall, 1992; Coggeshall and Lekan, 1996; Oo et al., 1996).

Neurochemical analyses. HPLC with electrochemical detection was used to measure striatal levels of dopamine (DA), 3,4dihydroxyphenylacetic acid (DOPAC), and homovanillic acid (HVA) as described previously (Przedborski et al., 1996). P24 mice were killed by cervical dislocation, the brains were quickly removed, and the caudateputamen was dissected onto an ice-cold glass Petri dish. Samples were immediately frozen on dry ice and stored at $-80^{\circ} \mathrm{C}$ until analysis. Dopamine and two of its metabolites, DOPAC and HVA, were analyzed and quantitated by HPLC using a $5 \mu \mathrm{m}$ C- 18 reverse-phase column and precolumn (Brownlee Labs, Wellesley, MA) followed by electrochemical detection with a glassy carbon electrode as described previously (Klivenyi et al., 2000).

Microarray and reverse transcription-PCR. Total RNA from P7 cerebella and P24 midbrain of $+/+$ and $w v / w v$ mice ( $n=4$ per group) were extracted manually using Trizol-chloroform and DNase treated with DNA-free solution (Ambion, Austin, TX). Quality control of RNA was performed using an Aglient 2100 Bioanalyzer. Only samples that passed this quality control were used for subsequent amplication and labeling. RNA was routinely amplified using one round of linear amplification using a MessageAmp aRNA Amplification kit (Ambion) and was labeled using an Array 350RP Genosphere kit (Genisphere, Hatfield, PA). Microarrays used in this study consisted of 23,000 mouse cDNA feature arrays, which were printed on MWG epoxy slides at the Buck Institute Genomics facility, and hybridized and washed on Lucidia HybPro (GE Healthcare, Arlington Heights, IL) automated hybstations. Hybridized arrays were then scanned on Packard Bioscience (Meridian, CT) scanners using balanced power settings for each dye. Quantitation of the resultant images was performed using Genepix (Axon, version 4.1) using default settings for background subtraction. All analyses were performed in the computing environment $\mathrm{R}$ (version 1.8) running on a G4 Macintosh, and all subsequent calculations were performed using the limma package (available at www.bioconductor.org). Briefly, Lowess subgrid normalization was performed and differential expression was evaluated between the samples via ranking of genes in decreasing probable order of differential expression after correcting for multiple testing. Candidate genes were then picked from this list for validation via real-time PCR using preoptimized Taq-man primers purchased from the assay on demand collection from ABI. Reverse transcription (RT)-PCR was performed on an automated ABI prism 7000 RT-PCR machine in 96-well format. Each sample was assessed in quadruplicate in $10 \mu \mathrm{l}$ total volume using $10 \mathrm{ng}$ equivalents of reverse transcribed RNA.

Primary mesencephalic cultures. Primary mesencephalic cell cultures were prepared from embryonic gestation day 14 (E14) to E15 mouse embryos as described previously (Peng et al., 2005). Briefly, dissociated cells were seeded 
A
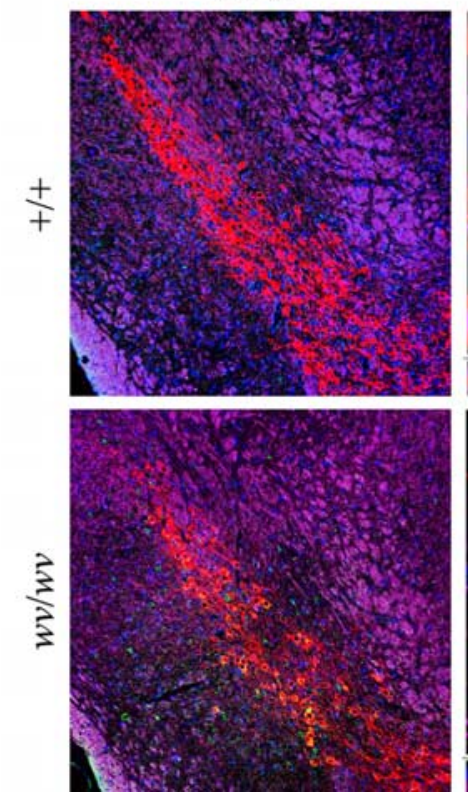

$3 \mathrm{D}$
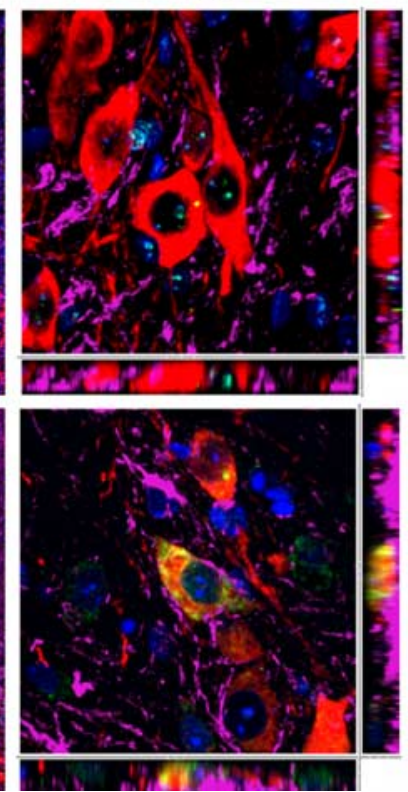

B
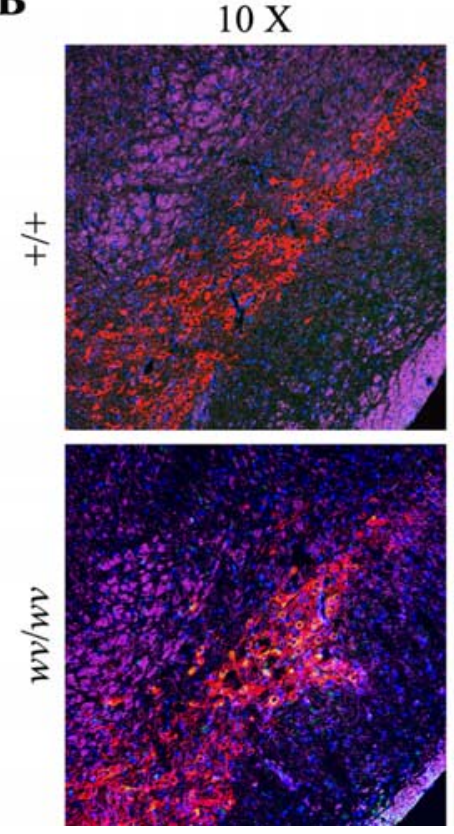

3D
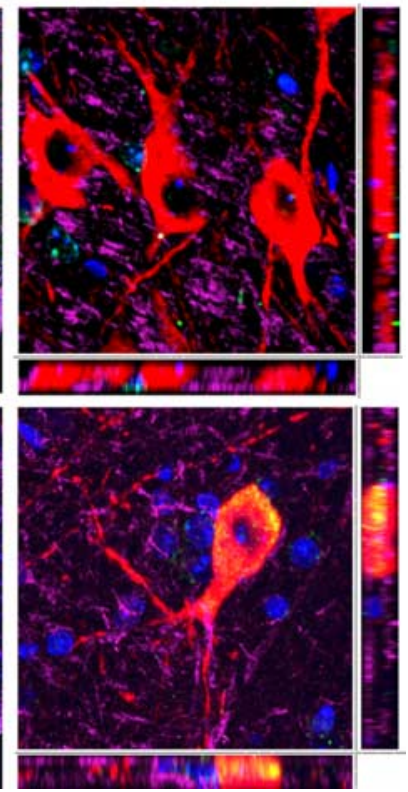

Figure 1. Immunofluorescence detection of MHC class I and $\beta 2$-microglobin proteins in TH-positive cells of the weaver SNpc. $A, Q$ uadruple labeling shows immunostaining for MHC Class I (green), TH (red), GFAP (purple), and counterstained with DAPI (blue) in the SNpc of $+/+$ and wv/wv mice. B, Quadruple labeling demonstrates immunostaining for $\beta 2$-microglobulin (green), TH (red), GFAP (purple), and counterstained with DAPI (blue) in the SNpc of $+/+$ and wv/wv mice. Original magnification, $10 \times$; three-dimensional (3D) magnification, $100 \times$. Note that TH + cells demonstrate colocalization with both neuroinflammatory markers (yellow) but not GFAP-positive cells.

at $7 \times 10^{5}$ cells per well onto poly-D-lysine-coated 24 -well culture plates. Cultures were maintained at $37^{\circ} \mathrm{C}$ in a humidified atmosphere containing 95\% air and 5\% carbon dioxide in Neurobasal medium (Invitrogen) containing 2\% B27 supplement, $2 \mathrm{~mm}$ glutamate, $100 \mathrm{U} / \mathrm{ml}$ penicillin, and 100 $\mu \mathrm{g} / \mathrm{ml}$ streptomycin. Cells were treated with or without $20 \mu \mathrm{M}$ minocycline for $8 \mathrm{~d}$. The number of TH-positive neurons in mesencephalic cultures was determined as described previously (Peng et al., 2005).

Western blot analysis. Total protein was isolated from brain tissue as described previously (Peng et al., 2004). Protein concentration of the supernatant was determined using a commercially available protein assay kit (Bio-Rad, Hercules, CA). Equal concentrations of protein extracts were electrophoretically resolved on SDS-polyacrylamide gels and transferred to PVDF membranes. After transfer, the membrane was blocked with Tris-buffered saline containing $0.05 \%$ Tween 20 (TBS-T) and 5\% milk for $60 \mathrm{~min}$, incubated with the primary antibody at the appropriate dilution (mouse anti-CD11b, 1:1000; mouse anti- $\beta$-actin, 1:5000) in TBS-T with $5 \%$ low-fat milk at $4^{\circ} \mathrm{C}$ overnight. Detection was performed using horseradish peroxidase-conjugated secondary antibody and an ECL kit (GE Healthcare).

Behavioral testing. Spontaneous locomotor activity was measured in an automated Tru Scan photobeam activity system (Coulbourn Instruments, Allentown, PA) under illumination (Peng et al., 2002). Animals were habituated to the apparatus for $15 \mathrm{~min}$ before running the experiment. Behavioral data were collected in the apparatus over a $10 \mathrm{~min}$ period and then analyzed using Tru Scan 99 software (Coulbourn Instruments).

Statistical analysis. All data are expressed as mean \pm SEM for the number $(n)$ of independent experiments performed. Differences among the means for all experiments described were analyzed using one- or two-way ANOVA. Newman-Keuls post hoc analysis was used when differences were observed by ANOVA testing $(p<0.05)$.

\section{Results}

Nigrostriatal dopaminergic cell death in the weaver is, in contrast to cerebellar granular loss, via a noncaspasemediated mechanism

In a previous study from our laboratory, we demonstrated that cerebellar granular cell death associated with the murine Girk $2 w v$ mutation was caspase mediated and could be attenuated by neuronal transgenic expression of the general caspase inhibitor baculoviral p35 protein (Peng et al., 2002). In this study, we first determined that neuronal $\mathrm{p} 35$ expression was unable to attenuate dopaminergic nigrostriatal degeneration associated with the Grk2wv mutation, suggesting that, unlike in the weaver cerebellum, cell death in the midbrain dopaminergic neurons is via a noncaspase-mediated mechanism (supplemental Figs. 1, 2, available at www.jneurosci.org as supplemental material).

\section{Girk $2 w v$ results in neuroinflammation in the weaver $\mathrm{SNpc}$}

To elucidate the possible mechanism(s) responsible for nigrostriatal dopaminergic cell loss in the weaver mouse, we performed microarray analysis followed by RT-PCR verification in an attempt to identify genes altered during the period of $w v / w v \mathrm{SNpc}$ cell loss in this brain region. The gene demonstrating the largest upregulation of expression by RT-PCR in the SNpc (360\%) was $\beta 2$-microglobulin, a chaperone for MHC class I molecules, which play a central role in antigen presentation and immunoglobulin transport (Tysoe-Calnon et al., 1991). Several MHC class I precursor proteins $\left(\mathrm{H}-2 \mathrm{D}^{\mathrm{b}} \alpha\right.$ chain, $\mathrm{H}-2 \mathrm{D}^{\mathrm{d}} \alpha$ chain, $\mathrm{H}-2 \mathrm{~K}^{\mathrm{b}} \alpha$ chain, and $\mathrm{H}-2 \mathrm{~L}^{\mathrm{d}} \alpha$ chain) also demonstrated significant upregulation of expression in the weaver SNpc.

To determine the levels of protein expression of $\beta 2$ microglobulin and associated class I molecule proteins in the weaver midbrain, which demonstrated mRNA upregulation during the period of Girk $2 w v$-induced midbrain neurodegeneration, tissue sections from $\mathrm{P} 24+/+$ or $w v / w v$ mice brains were immunostained against both $\mathrm{H}-2 \mathrm{~K}^{\mathrm{b}} \mathrm{MHC}$ class I alloantigen and $\beta 2$ microglobulin (Fig. $1 A, B$ ). MHC class I alloantigen and $\beta 2$ microglobulin were not detectable in $\mathrm{TH}$-positive neurons and astrocytes of $+/+$ mice; however, MHC class I alloantigen and $\beta 2$-microglobulin demonstrated robust expression in the $\mathrm{TH}$ positive neurons but not astrocytes of $w v / w v$ mice. 
A
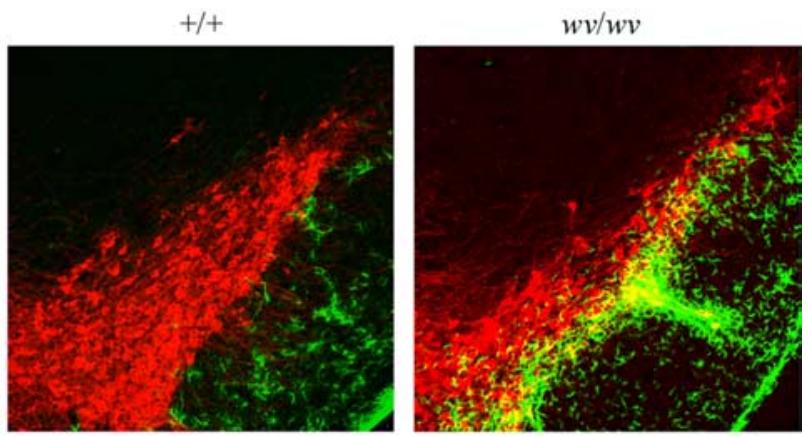

B

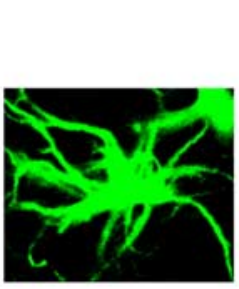

D

C

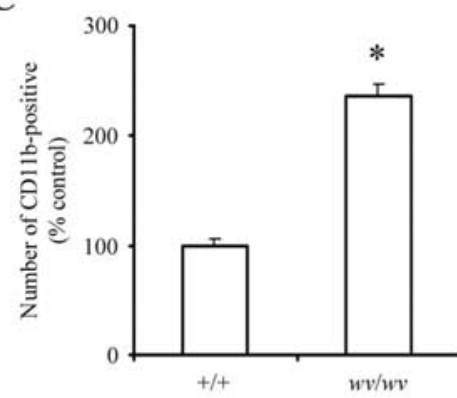

Figure 2. Microglial activation in the weaver SNpc. $\boldsymbol{A}, \mathrm{CD} 11 \mathrm{~b}$-positive microglia (green) and TH-positive neurons (red) in SNpc of $+/+$ and $w v / w v$ mice. Original magnification, $10 \times . \boldsymbol{B}$, Photomicrograph of representative activated microglial cell in the $w v / W v$ SNpc. Original magnification, $40 \times$. C, Quantitative analysis of the number of activated microglia in $+/+$ versus $w v / w v$ SNpc. Mean \pm SEM, $n=6 .{ }^{*} p<0.001 w v / w v$ significantly different from $+/+$. C, Western blot analysis of CD11b protein levels in $w v / w v$ and $+/+$ midbrain; $\beta$-actin was used as a loading control.

Elevations in MHC class I and $\beta 2$-microglobulin protein levels in the brain are traditionally associated with microglial activation. Activation of microglia is a common phenomenon associated with neuronal injury associated with several neurodegenerative diseases including PD (Gao et al., 2003; Hunot and Hirsch, 2003). To determine whether Girk $2 w v$-induced nigrostriatal dopaminergic neurodegeneration is associated with a heightened microglial response, we examined the expression of CD11b, a specific marker for activated microglia, in $w v / w v$ mice versus $+/+$ littermate controls. In contrast to $\mathrm{P} 24+/+$ mice, numerous robustly immunoreactive CD11b-positive activated microglia were noted in the SNpc of P2 $4 w v / w v$ mice (Fig. $2 A-C$ ). In $w v / w v$ mice, ventral midbrain CD11b-positive activated microglia increased by $\sim 137 \pm 5 \%$. Immunostaining with isolectin B-4, another marker for microglia, resulted in similar observations (data not shown). Differences in levels of CD11b in the weaver SNpc were verified via Western blot analysis (Fig. 2D).

Pharmacological treatment of weaver mice with the anti-inflammatory agent minocycline attenuates Girk $2 w v$-induced nigrostriatal dopaminergic neurodegeneration and locomotor dysfunction

Minocycline, a pharmacological anti-inflammatory and inhibitor of microglial activation, has been reported previously to protect nigrostriatal dopaminergic neurons from the neurotoxic effects of 1-methyl-4-phenyl-1,2,3,6-hydropyridine (MPTP) administration (Du et al., 2001; Wu et al., 2002). To examine

A

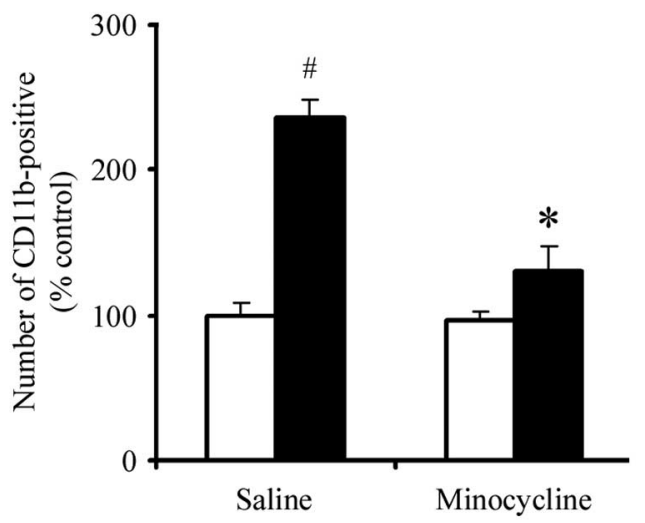

B

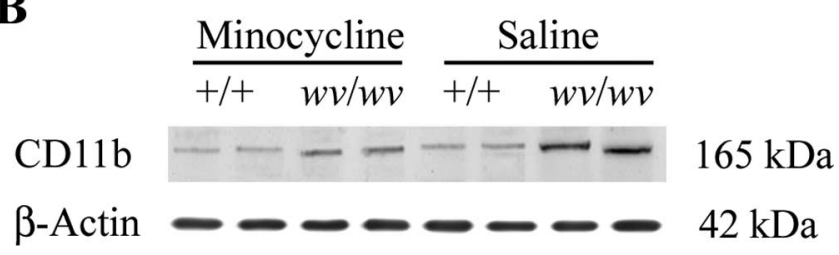

Figure 3. Minocycline attenuates microglia activation in the weaver SNpc. A, Quantitative analysis of the number of activated microglia from $+/+$ (white bars) or $w v / w v$ (black bars) mice. Mean $\pm \mathrm{SEM}, n=3 .{ }^{*} p<0.001 \mathrm{wv} / \mathrm{wv}$ significantly different from $+/+{ }^{*}{ }^{*} p<0.01$ $w v / w v$ plus minocycline significantly different from $w v / w v$ alone. $\boldsymbol{B}$, Western blot analysis of SNpc CD11b protein levels; $\beta$-actin was used as a loading control.

whether minocycline blocks Girk2wv-mediated microglial activation in the weaver mouse, the expression of CD11b was analyzed by immunostaining in SNpc tissues. As shown in Figure 3A, pretreatment with minocycline was found to significantly suppress the number of activated microglia. Indeed, counts of CD11b-positive activated microglia were not significantly different in the SNpc of $w v / w v$ mice administered minocycline compared with $+/+$ controls. Levels of CD11b protein in the weaver $\mathrm{SNpc}$ were also found to be reduced in the presence of minocycline administration (Fig. $3 B$ ).

To assess whether inhibition of microglial activation via minocycline is capable of affording neuroprotection against midbrain dopaminergic cell loss in the weaver mouse, we further assessed the effects of treatment of primary mesencephalic cultures isolated from either $+/+$ or $w v / w v$ mice with minocycline on dopaminergic cell survival. Cells were stained for $\mathrm{TH}$ at $8 \mathrm{~d}$ after minocycline treatment, and $\mathrm{TH}$-positive cells were counted. As demonstrated in Figure 4, treatment with minocycline (20 $\mu \mathrm{M})$ significantly protected cultured midbrain $\mathrm{TH}$-positive neurons from Girk $2 w v$-induced dopaminergic cell death, reducing dopaminergic midbrain cell loss from 50 to $20 \%$.

To examine whether inhibition of microglial activation via minocycline administration afforded protection against loss of $w v / w v$ SNpc dopaminergic neurons in vivo, we stereologically counted TH-positive SNpc neurons from $w v / w v$ mice after oral administration of either minocycline or vehicle alone from P10 through P24 versus +/+ littermate controls. As demonstrated in Figure 5, administration of minocycline protected against Girk $2 w v$-induced dopaminergic neuron loss, reducing losses by $\sim 42 \%$ in the SNpc of $w v / w v$ mice treated with minocycline compared with $w v / w v$ controls, suggesting a critical role for neuroinflammation in Girk $2 w v$-mediated nigral dopaminergic neuronal death. 
A
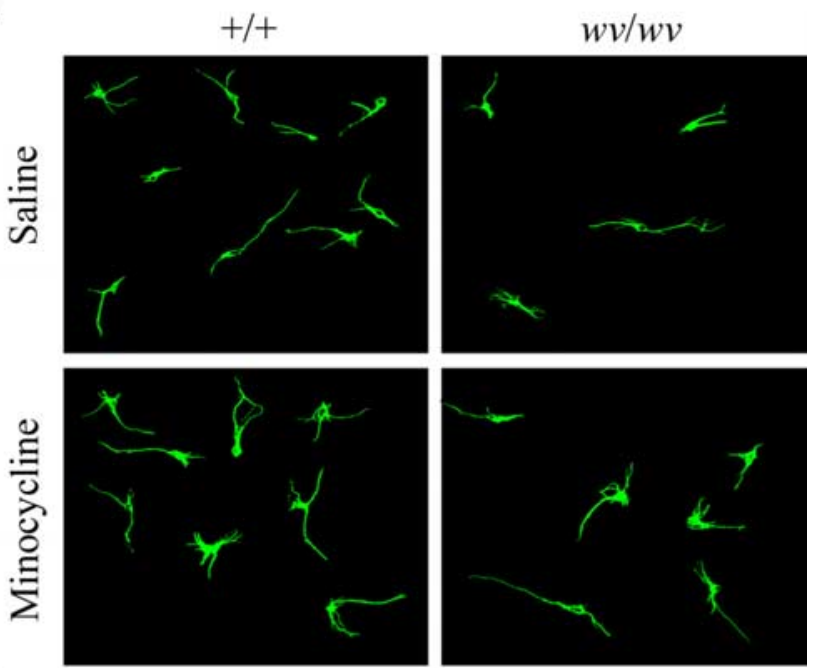

B

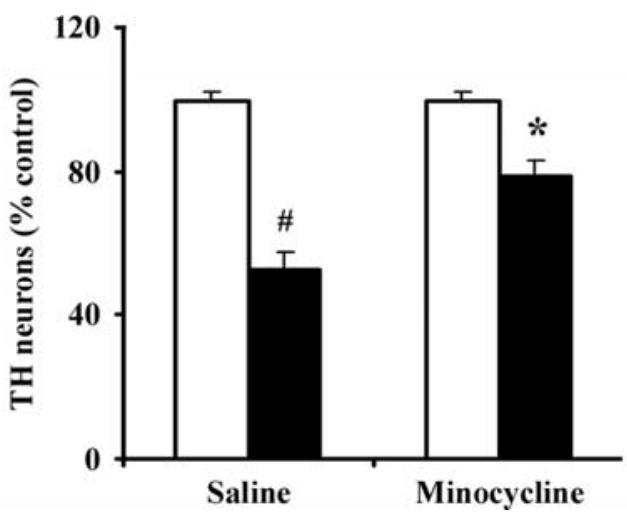

Figure 4. Protective effects of minocycline administration on weaver nigral dopaminergic neuronal damage in vitro. $\boldsymbol{A}$, Photomicrographs of TH-positive neurons (green) in primary mesencephalic cultures. $\boldsymbol{B}$, TH-positive neuron counts in primary mesencephalic cultures from $+/+$ (white bars) or $w v / w v$ (black bars) mice. Mean \pm SEM, $n=5 .{ }^{\#} p<0.001 w v / w v$ significantly different from $+/+;{ }^{*} p<0.01 \mathrm{wv} / \mathrm{wv}$ plus minocycline significantly different from $w v / w v$ alone.

The weaver mouse behavioral phenotype is characterized by ataxia, curled posture, gait instability, hypertonia, and tremor (Sidman et al., 1965). This is attributed to the combined death of both the cerebellar granular neurons and midbrain dopaminergic cells. We assessed whether the minocycline-mediated protection against Girk2wv-mediated SNpc dopaminergic neurodegeneration resulted in an attenuation of previously observed locomotor deficits in the weaver (Peng et al., 2002). Locomotor activity of $+/+$ and $w v / w v$ mice was compared as previously on a battery of behavioral tests in an open-field environment, including measurements of total movements, movement time, movement distance, and mean velocity. Weaver mice receiving minocycline exhibited significant recovery of locomotor activity compared with $w v / w v$ controls (Fig. 6). Weaver mice treated with minocycline were also noted to have normal posture and attenuated rigidity, however, did not display a significant reduction in ataxia as had been observed previously in weaver mice with reduced cerebellar cell death as a consequence of expression of the baculoviral antiapoptotic p35 gene.

\section{Discussion}

Two well-known neuronal subtypes that undergo neurodegeneration as a consequence of the Girk $2 w v$ mutation are dopami-
A
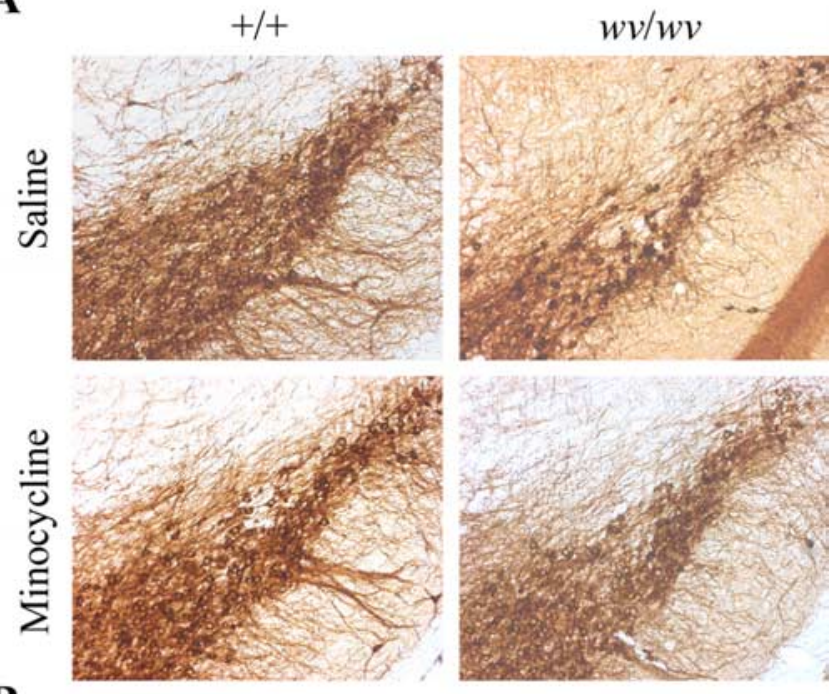

B

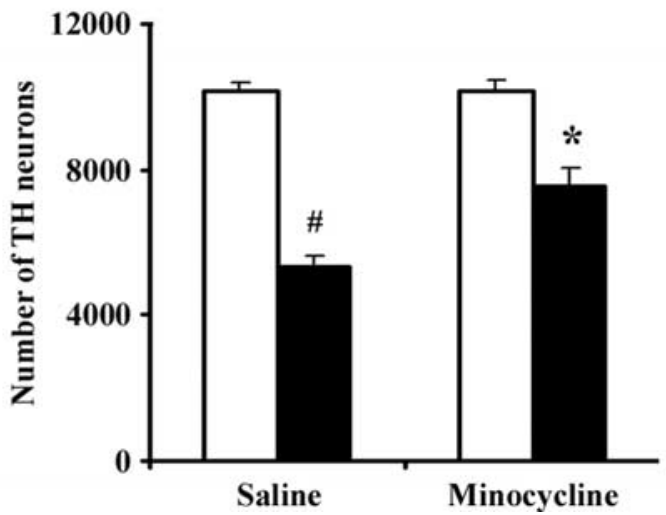

Figure 5. Oral administration of minocycline protects degeneration of the weaver SNpc dopaminergic neurons in vivo. $\boldsymbol{A}$, Photomicrographs of TH-positive sections. $\boldsymbol{B}$, Quantitative stereological analysis of the number of TH-positive profiles from $+/+$ (white bars) or wv/wv (black bars) SNpc. Mean \pm SEM, $n=4$. ${ }^{*} p<0.001 w v / w v$ significantly different from $+/+$; ${ }^{*} p<0.01 \mathrm{wv} / \mathrm{wv}$ plus minocycline significantly different from $w v / w v$ alone.

nergic neurons of the ventral midbrain and granule neurons of the cerebellum. These two populations have in common the expression of the Girk 2 channel, the fact that presence of the $w v / w v$ version of the channel kills large numbers of each population postnatally, and that neuronal cell death occurs after the completion of mitosis and before completion of differentiation. They differ in that most of the vulnerable cerebellar granule neurons die almost immediately after completing mitosis in the ECL before their migration to the internal granule neuron layer (Rezai and Yoon, 1972; Rakic and Sidman, 1973a,b; Smeyne and Goldowitz, 1989), whereas the dopaminergic neurons die long after completion of mitosis and their migration to their proper location in the ventral midbrain (Schmidt et al., 1982; Roffler-Tarlov and Graybiel, 1984; Triarhou et al., 1988; Graybiel et al., 1990; Roffler-Tarlov et al., 1996). There are, in addition, no doubt scores of additional intrinsic differences between granule neurons and nigrostriatal dopaminergic neurons in the weaver mouse that might differentially impact how these neuronal populations die. Dying neurons in these two groups have different morphological characteristics as a consequence of the presence of the Girk $2 w v$ mutation. Cerebellar granule neurons in the weaver mouse demonstrate characteristics of apoptotic cell death, in- 
A

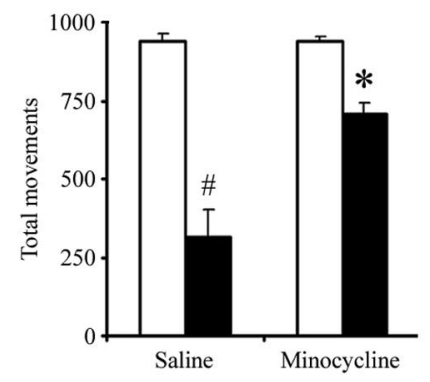

C

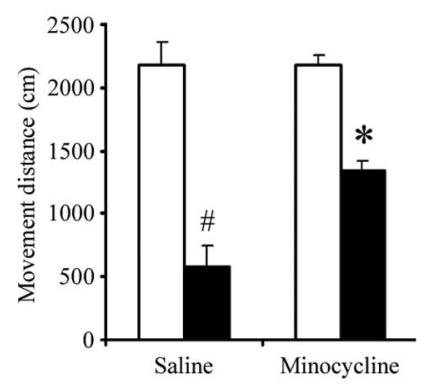

B

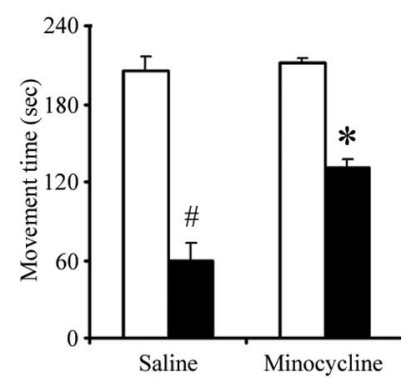

D

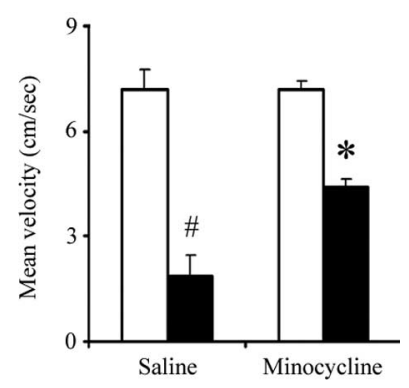

Figure 6. Locomotor deficits in weaver mice are attenuated by oral minocycline administration. All experiments were performed during a 10 min trial period after 15 min of habituation to the apparatus. $\boldsymbol{A}$, Total movements. $\boldsymbol{B}$, Movement time. $\boldsymbol{C}$, Movement distance. $\boldsymbol{D}$, Mean velocity. Sample sizes were $6(+/+$, saline), 4 (wv/wv, saline), $6(+/+$, minocycline), and 6 ( $w v / w v$, minocycline). Mean $\pm \mathrm{SEM},{ }^{\#} p<0.001 w v / w v$ significantly different from $+/+$; ${ }^{*} p<0.01 w v / w v$ plus minocycline significantly different from $w v / w v$ alone.

cluding chromatin condensation and aggregation to the nuclear margin, cytoplasmic shrinkage, membrane blebbing, and DNA fragmentation that is detectable by DNA end-labeling (Smeyne and Goldowitz, 1989; Migheli et al., 1995; Harrison and RofflerTarlov, 1998; Peng et al., 2002). Dopaminergic SNpc neurons are capable of undergoing apoptotic cell death both during normal development and in response to various neurotoxins such as MPTP and 6-hydroxydopamine (6-OHDA) (Offen et al., 1998; Viswanath et al., 2001; Nicotra and Parvez, 2002; Serra et al., 2002). However, dying dopaminergic neurons in the weaver mouse, in contrast, does not display DNA end-labeling or other morphological characteristics of apoptosis (Oo et al., 1996; Harrison and Roffler-Tarlov, 1998). We previously reported that expression of a transgene encoding baculoviral p35 attenuates cerebellar granule neuronal death in $w v / w v$ mice and improves behavioral deficits caused by the Girk $2 w v$ mutation (Peng et al., 2002). In contrast, we report here that p35 expression does not protect dopaminergic neurons in the ventral midbrain. It is clear that the same mutation results in a different mode of cell death in the dopaminergic midbrain neurons versus the cerebellar granule neurons of the weaver mouse, and these result in morphologically distinct forms of neuronal death observed in the two affected neuronal populations. The molecular mechanism(s) involved in the selective nigrostriatal dopaminergic cell death in the weaver mouse has remained relatively unexplored.

The data from this present study demonstrate that dopaminergic SNpc neurons undergoing neurodegeneration in the weaver mouse express both MHC class I and $\beta 2$-microglobin. Girk $2 w v$-induced dopaminergic neuronal loss in the $\mathrm{SN}$ in vivo is also accompanied by significant microglial activation as detected by CD11b immunocytochemistry. Furthermore, inhibition of

neuroinflammation via the anti-inflammatory agent minocycline significantly protects against the nigrostriatal dopaminergic neuronal death as well as improving locomotor deficits. Taken in total, these data suggest that neuroinflammation plays a critical role in cell death associated with the selective nigrostriatal dopaminergic degeneration in the weaver mouse. Neuroinflammation is a prominent characteristic of neurodegeneration associated with several neurodegenerative diseases, including PD. It is also observed in several murine models of the disorder including systemic acute MPTP (Kurkowska-Jastrzebska et al., 1999; Du et al., 2001; Wu et al., 2002) and chronic rotenone administration (Sherer et al., 2003) and intrastriatal 6-OHDA infusion (He et al., 2001). Degeneration of dopaminergic neurons in the human disorder is accompanied by massive microglial activation (McGeer et al., 1988). Microglial activation has also been noted postmortem in both humans and primates exposed to MPTP (Langston et al., 1999; McGeer et al., 2003) and in the chronic mouse rotenone model before appearance of the dopaminergic lesion (Sherer et al., 2003). MHC class I antigens are readily upregulated in the CNS as a consequence of cell injury or infection. MHC class I molecules, together with $\beta 2$-microglobulin, play an important role in immune responses to antigen (Pamer and Cresswell, 1998). Both have been reported to be upregulated in association with degenerating dopaminergic neurons and microglia in the PD SN as well as in the MPTP mouse model in association with T cell infiltration and proinflammatory cytokines (McGeer et al., 1987; Mogi et al., 1995; Kurkowska-Jastrzebska et al., 1999; Linda et al., 1999). As has been noted previously, there are a number of analogous changes, including dopamine concentrations and nigrostriatal dopaminergic cell loss, in the weaver mouse and in Parkinson patients (Schmidt et al., 1982; Roffler-Tarlov and Graybiel, 1984; Triarhou et al., 1988; Graybiel et al., 1990; Roffler-Tarlov et al., 1996). There are differences between midbrain dopaminergic cell loss in the weaver mouse versus the human disorder, including the fact that $\mathrm{PD}$ is a progressive disease of which the incidence increases markedly with age (Forno, 1996; Lang and Lozano, 1998), whereas comparable neuronal cell loss in the weaver occurs in early adult life and is essentially nonprogressive (Schmidt et al., 1982; Roffler-Tarlov and Graybiel, 1984; Triarhou et al., 1988; Graybiel et al., 1990; Roffler-Tarlov et al., 1996). However, given the data presented here, the weaver may serve as an important model for the impact of neuroinflammation on this particular cell type, including in PD.

Minocycline, a semisynthetic second-generation tetracycline, easily penetrates the blood-brain barrier and has been shown recently to have effective neuroprotective properties in other mouse disease models, including amyotrophic lateral sclerosis, cerebral ischemia, Huntington's disease, multiple sclerosis, and spinal cord injury (Domercq and Matute, 2004), all of which cause neuron degeneration as a consequence of inflammation. In addition, minocycline treatment has been found to attenuate 6-OHDA- and MPTP-induced dopaminergic neurodegeneration (Du et al., 2001; He et al., 2001; Wu et al., 2002). Our data suggest that neuroinflammation is critical to the demise of SNpc dopaminergic neurons in the weaver mouse. Given that neuroinflammation is a major mediator of dopaminergic neurodegeneration associated with the same set of neurons in PD and in several animal models of the disorder, this has important novel implications for the use of weaver as a model for this particular aspect of the disease as well as for testing anti-inflammatory agents as PD-related therapies. 


\section{References}

Blatt GJ, Eisenman LM (1985) A qualitative and quantitative light microscopic study of the inferior olivary complex of normal, reeler, and weaver mutant mice. J Comp Neurol 232:117-128.

Caviness Jr VS, Rakic P (1978) Mechanisms of cortical development: a view from mutations in mice. Annu Rev Neurosci 1:297-326.

Coggeshall RE (1992) A consideration of neural counting methods. Trends Neurosci 15:9-13.

Coggeshall RE, Lekan HA (1996) Methods for determining numbers of cells and synapses: a case for more uniform standards of review. J Comp Neurol 364:6-15.

Domercq M, Matute C (2004) Neuroprotection by tetracyclines. Trends Pharmacol Sci 25:609-612.

Du Y, Ma Z, Lin S, Dodel RC, Gao F, Bales KR, Triarhou LC, Chernet E, Perry KW, Nelson DL, Luecke S, Phebus LA, Bymaster FP, Paul SM (2001) Minocycline prevents nigrostriatal dopaminergic neurodegeneration in the MPTP model of Parkinson's disease. Proc Natl Acad Sci USA 98:14669-14674.

Forno LS (1996) Neuropathology of Parkinson's disease. J Neuropathol Exp Neurol 55:259-272.

Galvan V, Gorostiza OF, Banwait S, Ataie M, Logvinova AV, Sitaraman S, Carlson E, Sagi SA, Chevallier N, Jin K, Greenberg DA, Bredesen DE (2006) Reversal of Alzheimer's-like pathology and behavior in human APP transgenic mice by mutation of Asp664. Proc Natl Acad Sci USA 103:7130-7135.

Gao HM, Liu B, Zhang W, Hong JS (2003) Novel anti-inflammatory therapy for Parkinson's disease. Trends Pharmacol Sci 24:395-401.

Graybiel AM, Ohta K, Roffler-Tarlov S (1990) Patterns of cell and fiber vulnerability in the mesostriatal system of the mutant mouse weaver. I. Gradients and compartments. J Neurosci 10:720-733.

Harrison SM, Roffler-Tarlov SK (1998) Cell death during development of testis and cerebellum in the mutant mouse weaver. Dev Biol 195:174-186.

He Y, Appel S, Le W (2001) Minocycline inhibits microglial activation and protects nigral cells after 6-hydroxydopamine injection into mouse striatum. Brain Res 909:187-193.

Herrup K, Trenkner E (1987) Regional differences in cytoarchitecture of the weaver cerebellum suggest a new model for weaver gene action. Neuroscience 23:871-885.

Hunot S, Hirsch EC (2003) Neuroinflammatory processes in Parkinson's disease. Ann Neurol 53:S49-S60.

Klivenyi P, Andreassen OA, Ferrante RJ, Dedeoglu A, Mueller G, Lancelot E, Bogdanov M, Andersen JK, Jiang D, Beal MF (2000) Mice deficient in cellular glutathione peroxidase show increased vulnerability to malonate, 3-nitropropionic acid, and 1-methyl-4-phenyl-1,2,5,6-tetrahydropyridine. J Neurosci 20:1-7.

Kurkowska-Jastrzebska I, Wronska A, Kohutnicka M, Czlonkowski A, Czlonkowska A (1999) The inflammatory reaction following 1-methyl4-phenyl-1,2,3, 6-tetrahydropyridine intoxication in mouse. Exp Neurol 156:50-61.

Lang AE, Lozano AM (1998) Parkinson's disease. First of two parts. N Engl J Med 339:1044-1053.

Langston JW, Forno LS, Tetrud J, Reeves AG, Kaplan JA, Karluk D (1999) Evidence of active nerve cell degeneration in the substantia nigra of humans years after 1-methyl-4-phenyl-1,2,3,6-tetrahydropyridine exposure. Ann Neurol 46:598-605.

Linda H, Hammarberg H, Piehl F, Khademi M, Olsson T (1999) Expression of MHC class I heavy chain and beta2-microglobulin in rat brainstem motoneurons and nigral dopaminergic neurons. J Neuroimmunol 101:76-86.

Maricich SM, Soha J, Trenkner E, Herrup K (1997) Failed cell migration and death of purkinje cells and deep nuclear neurons in the weaver cerebellum. J Neurosci 17:3675-3683.

McGeer PL, McGeer EG, Itagaki S, Mizukawa K (1987) Anatomy and pathology of the basal ganglia. Can J Neurol Sci 14:363-372.

McGeer PL, Itagaki S, Boyes BE, McGeer EG (1988) Reactive microglia are positive for HLA-DR in the substantia nigra of Parkinson's and Alzheimer's disease brains. Neurology 38:1285-1291.

McGeer PL, Schwab C, Parent A, Doudet D (2003) Presence of reactive microglia in monkey substantia nigra years after 1-methyl-4-phenyl1,2,3,6-tetrahydropyridine administration. Ann Neurol 54:599-604.

Migheli A, Attanasio A, Lee WH, Bayer SA, Ghetti B (1995) Detection of apoptosis in weaver cerebellum by electron microscopic in situ endlabeling of fragmented DNA. Neurosci Lett 199:53-56.

Migheli A, Piva R, Wei J, Attanasio A, Casolino S, Hodes ME, Dlouhy SR, Bayer SA, Ghetti B (1997) Diverse cell death pathways result from a single missense mutation in weaver mouse. Am J Pathol 151:1629-1638.

Migheli A, Piva R, Casolino S, Atzori C, Dlouhy SR, Ghetti B (1999) A cell cycle alteration precedes apoptosis of granule cell precursors in the weaver mouse cerebellum. Am J Pathol 155:365-373.

Mogi M, Harada M, Kondo T, Riederer P, Nagatsu T (1995) Brain beta 2-microglobulin levels are elevated in the striatum in Parkinson's disease. J Neural Transm Park Dis Dement Sect 9:87-92.

Nicotra A, Parvez S (2002) Apoptotic molecules and MPTP-induced cell death. Neurotoxicol Teratol 24:599-605.

Offen D, Beart PM, Cheung NS, Pascoe CJ, Hochman A, Gorodin S, Melamed E, Bernard R, Bernard O (1998) Transgenic mice expressing human $\mathrm{Bcl}-2$ in their neurons are resistant to 6-hydroxydopamine and 1-methyl4-phenyl-1,2,3,6- tetrahydropyridine neurotoxicity. Proc Natl Acad Sci USA 95:5789-5794.

Oo TF, Blazeski R, Harrison SM, Henchcliffe C, Mason CA, Roffler-Tarlov SK, Burke RE (1996) Neuron death in the substantia nigra of weaver mouse occurs late in development and is not apoptotic. J Neurosci 16:6134-6145.

Pamer E, Cresswell P (1998) Mechanisms of MHC class I-restricted antigen processing. Annu Rev Immunol 16:323-358.

Patil N, Cox DR, Bhat D, Faham M, Myers RM, Peterson AS (1995) A potassium channel mutation in weaver mice implicates membrane excitability in granule cell differentiation. Nat Genet 11:126-129.

Peng J, Wu Z, Wu Y, Hsu M, Stevenson FF, Boonplueang R, Roffler-Tarlov SK, Andersen JK (2002) Inhibition of caspases protects cerebellar granule cells of the weaver mouse from apoptosis and improves behavioral phenotype. J Biol Chem 277:44285-44291.

Peng J, Mao XO, Stevenson FF, Hsu M, Andersen JK (2004) The herbicide paraquat induces dopaminergic nigral apoptosis through sustained activation of the JNK pathway. J Biol Chem 279:32626-32632.

Peng J, Stevenson FF, Doctrow SR, Andersen JK (2005) Superoxide dismutase/catalase mimetics are neuroprotective against selective paraquatmediated dopaminergic neuron death in the substantial nigra: implications for Parkinson disease. J Biol Chem 280:29194-29198.

Przedborski S, Jackson-Lewis V, Yokoyama R, Shibata T, Dawson VL, Dawson TM (1996) Role of neuronal nitric oxide in 1-methyl-4-phenyl1,2,3,6-tetrahydropyridine (MPTP)-induced dopaminergic neurotoxicity. Proc Natl Acad Sci USA 93:4565-4571.

Rakic P, Sidman RL (1973a) Sequence of developmental abnormalities leading to granule cell deficit in cerebellar cortex of weaver mutant mice. J Comp Neurol 152:103-132.

Rakic P, Sidman RL (1973b) Organization of cerebellar cortex secondary to deficit of granule cells in weaver mutant mice. J Comp Neurol 152:133-161.

Rezai Z, Yoon CH (1972) Abnormal rate of granule cell migration in the cerebellum of "Weaver" mutant mice. Dev Biol 29:17-26.

Roffler-Tarlov S, Graybiel AM (1984) Weaver mutation has differential effects on the dopamine-containing innervation of the limbic and nonlimbic striatum. Nature 307:62-66.

Roffler-Tarlov S, Graybiel AM (1986) Expression of the weaver gene in dopamine-containing neural systems is dose-dependent and affects both striatal and nonstriatal regions. J Neurosci 6:3319-3330.

Roffler-Tarlov S, Martin B, Graybiel AM, Kauer JS (1996) Cell death in the midbrain of the murine mutation weaver. J Neurosci 16:1819-1826.

Savitz SI, Rosenbaum DM (1998) Apoptosis in neurological disease. Neurosurgery 42:555-572.

Schein JC, Hunter DD, Roffler-Tarlov S (1998) Girk2 expression in the ventral midbrain, cerebellum, and olfactory bulb and its relationship to the murine mutation weaver. Dev Biol 204:432-450.

Schmidt MJ, Sawyer BD, Perry KW, Fuller RW, Foreman MM, Ghetti B (1982) Dopamine deficiency in the weaver mutant mouse. J Neurosci 2:376-380.

Serra PA, Sciola L, Delogu MR, Spano A, Monaco G, Miele E, Rocchitta G, Miele M, Migheli R, Desole MS (2002) The neurotoxin 1-methyl-4phenyl-1,2,3,6-tetrahydropyridine induces apoptosis in mouse nigrostriatal glia. Relevance to nigral neuronal death and striatal neurochemical changes. J Biol Chem 277:34451-34461.

Sherer TB, Betarbet R, Kim JH, Greenamyre JT (2003) Selective microglial 
activation in the rat rotenone model of Parkinson's disease. Neurosci Lett 341:87-90.

Sidman RL, Green MC, Appel SH (1965) Catalog of the neurological mutants of the mouse. Cambridge, MA: Harvard UP.

Smeyne RJ, Goldowitz D (1989) Development and death of external granular layer cells in the weaver mouse cerebellum: a quantitative study. J Neurosci 9:1608-1620.

Smeyne RJ, Goldowitz D (1990) Purkinje cell loss is due to a direct action of the weaver gene in Purkinje cells: evidence from chimeric mice. Brain Res Dev Brain Res 52:211-218.

Triarhou LC, Norton J, Ghetti B (1988) Mesencephalic dopamine cell deficit involves areas A8, A9 and A10 in weaver mutant mice. Exp Brain Res 70:256-265.

Tysoe-Calnon VA, Grundy JE, Perkins SJ (1991) Molecular comparisons of the beta 2-microglobulin-binding site in class I major-histocompatibility- complex alpha-chains and proteins of related sequences. Biochem J 277:359-369.

Viswanath V, Wu Z, Fonck C, Wei Q, Boonplueang R, Andersen JK (2000) Transgenic mice neuronally expressing baculoviral p35 are resistant to diverse types of induced apoptosis, including seizure-associated neurodegeneration. Proc Natl Acad Sci USA 97:2270-2275.

Viswanath V, Wu Y, Boonplueang R, Chen S, Stevenson FF, Yantiri F, Yang L, Beal MF, Andersen JK (2001) Caspase-9 activation results in downstream caspase- 8 activation and bid cleavage in 1-methyl-4-phenyl1,2,3,6-tetrahydropyridine-induced Parkinson's disease. J Neurosci 21:9519-9528.

Wu DC, Jackson-Lewis V, Vila M, Tieu K, Teismann P, Vadseth C, Choi DK, Ischiropoulos H, Przedborski S (2002) Blockade of microglial activation is neuroprotective in the 1-methyl-4-phenyl-1,2,3,6-tetrahydropyridine mouse model of Parkinson disease. J Neurosci 22:1763-1771. 